consequences of large-scale interference with Nature, nothing but good can come of the scientists' work.

The first three papers at the Conference were on general subjects. In a general survey of eelworm problems, Dr. B. G. Peters dealt in broad terms with these insidious pests, which are often not detected until extensive damage has been caused. A general survey of soil pests affecting vegetable crops, by Mr. J. W. Wright, was the subject of the following paper, and a general survey on foliage diseases in arable crops, by Dr. H. E. Croxall, rounded off these introductory talks. Later papers dealt with more specialized aspects. In considering the economics of potato blight control, Mr. H. I. Kingston dealt with the search for substitutes to replace the now very expensive copper compounds, and it appears that small quantities of phenyl mercuric chloride can act as synergists and effect reductions in the use of copper up to 40 per cent. In a paper on virus problems in sugar beet, Dr. R. Hull told how loss due to this disease has been reduced in recent years, thanks to careful rogueing on steckling beds and liberal use of insecticides, especially the systemics. The last two papers of the day, control of pests in arable crops, by Mr. J. L. Hunt, and control of pests in Brassica seed crops, by Mr. S. G. Jary, drew much discussion on matters ranging from the forecasting of pest incidence to the amount of loss which can be suffered by seed brassicas without reduction of eventual yjeld.

The morning of November 2 was devoted to a series of papers on application problems and hazards. The application of materials to control pests and diseases of pea crops was dealt with by Mr. R. W. Shorrock and provoked a lively discussion, in which many references were made to the increasing recog. nition of eelworm as a widespread pest of this crop. The next paper, by Mr. F. W. Morris, on the advantages of high-versus low-volume spraying, was another which led to considerable controversy. Mr. Cameron Gifford, speaking on application aspects of aphis control in sugar beet, brassicas and related crops, emphasized the case for dusting in certain instances. Hazards were dealt with by Dr. E. F. Edson and Dr. J. M. Barnes for application and residue problems, respectively, in a pair of most interesting papers in which emphasis was laid upon the desirability of education for safety rather than 'blanket' legislation. The meeting then passed to consideration of seed dressings. Recent developments in the use and application of dual-purpose seed dressings - that is, of insecticide and fungicide seed dressings - was the subject of a review by Dr. D. Price Jones, and Mr. A. J. Pearson, in a paper on 'Dieldrin' seed dressings, described trials of this comparatively new insecticide against insect pests of the seed and seedling. Taint was discussed by Dr. M. Cohen, who described not only the cases of taint, in which benzene hexachloride is still the principal offender, but also the form of tests used for estimation of off-flavours. Dr. R. de B. Ashworth then gave an account of groups of new chemicals recently included in the crop-protection products approvals scheme.

The last day of the Conference opened with a consideration of glass-house problems. The first paper, by Dr. E. Taylor, dealt with the control of fungi under glass, and was followed by one on control of insects under glass, read by Mr. W. H. Read. The glass-house crops can be more efficiently dealt with bv fumigation and aerosol methods than those out of doors, but, on the other hand, their concentration within small spaces raises a number of its own problems. The remainder of the day was occupied with horticultural problems. Mr. J. E. Garnham, speaking on control of red spider on fruit, described the use of chlorbenzide against this serious pest, emphasizing the importance of its application early against winter eggs and immature mites, and condemned the use of the term 'ovicide' when applied to such a widely active compound. In considering the control of fruit pests other than red spider, Mr. E. L. Williams directed attention to the increasing use of insecticide sprays for pests against which winter washing used to be the standard treatment. In the ensuing discussion many suggestions were put forward for reducing the number of separate spraying operations by mixed applications of insecticides and fungicides. New techniques for the control of pests on hops were described by Mr. Emery, who showed some very spectacular slides on the effect of the insecticide dimefox applied to the soil beneath the bines. In reply to questions, he mentioned experiments showing first that the quantity of dimefox present in the hops on harvest is negligible, and secondly, that any which is present would certainly be destroyed in the process of brewing. Mr. E. J. Hainsworth then read a paper on recent advances in scab control, from which it appears that the growing use of captan and the organo-mercurials calls for discretion and that there is still a case to be made out for the use of sulphur. The final paper, on other aspects of the control of fungus diseases on fruit, by Mr. R. W. Marsh, stressed the inability of the newer scab-controlling insecticides to keep down the mildews which are at present controlled by means of sulphur sprays. $\mathrm{He}_{e}$ also spoke of experiments using phenyl mercuric chloride against apple tree canker.

\section{IONIZING RADIATION AND THE CELL}

A

SERIES of fourteen papers and an introduction by G. Pollard, which were presented at a conference of the New York Academy of Sciences on "Ionizing Radiation and the Cell", have now been collected as a separate issue of the Academy's Annals (59, Art. 3, 467-664 ; 1955 ; 4 dollars). For a very good reason the major part of this volume should be of absorbing interest for biologists in a number of different fields. It shows in a precise way, yet intelligible to those outside radiation biology, how varied are the methods now available which use ionizing radiations for analysing ultramicroscopic biological structures and their functions. This is more than can be said of the often ponderous other publications on radiation biology which have multiplied in recent years.

The essentials of the oldest and best-known radiation method are that localized releases of energy within a cell structure may cause it to lose or change one or more of its biological functions. Comparing loss of function caused by irradiation with different types and doses of radiation, one can infer something about the size, shape and molecular stability of the structures examined, and about the relations of these to function. This type of analysis has given useful results, for example, in the case of the structure and function of bacteriophage particles, of chromosomes and genes, and of various other cellular components. The same sort of analysis has been applied success. 
fully to large molecules: a paper by Setlow illustrates it very effectively for the case of certain enzymes and other proteins.

Several of the papers at this conference are based on the use of this inactivation method: one by Fluke and Pollard on bacteriophage ; one by Caldecott on barley; one by Bloom et al. on the use of microbeams $(2 \cdot 5-7 \mu$ in diameter) on tissue cultures of newt heart; and others. A paper by Giles et al., however, reports the use of radiation both to produce 'loss' mutations and to reverse them.

An elegant new use of ionizing radiations, intro. duced by Hutchinson, of the Biophysics Department at Yale University, is for probing structure by a sort of radiation sounding procedure. With charged particles such as electrons and protons in beams of controlled energy, it is possible to irradiate the outer layers of a biological system without producing any effect at a depth greater than the particle-range. This range varies in a known way with the kind and energy of the particles. Thus, by using a series of beams of increasing energy, one can probe deeper and deeper into the system. When this is done, discontinuity of structure may become quite clear. For example, inactivation of bacteriophage $T-1$ with slow electrons shows a steep rise between 700 and 1,100 volts, and from this Hutchinson calculates that there is an insensitive outer layer about $125 \mathrm{~A}$. thick. This finding is in perfect agreement with those from the biochemistry and genetics of this phage, which is known to have a protein coating not essential for its multiplication, and an essential core of deoxyribonucleic acid.

All the other papers in this volume are well worth reading by the specialist, though perhaps for the non-specialist they are not as important as those already quoted.

G. Ponteconvo

\section{THE MELLON INSTITUTE \\ REPORT FOR 1954}

$\mathrm{T}$ HE annual report* of the president, Dr. E. R. Weidlein, to the Board of Trustees of the Mellon Institute on the scientific research activities of the Institute for the year ended February 28,1955 , notes the establishment of a new Department of Applied Mathematics to assist in formulating experimental designs and the statistical analysis of data, the installation of an electron microscope in the Department of Research in Chemical Physics, and the equipment of an air-conditioned laboratory for microchemical analysis and research in the Department of Analytical Chemistry. Expenditure on pure and applied research during the year was $4,784,344$ dollars, and, of this sum, just over a million dollars was spent on scientific research in the six research departments and on twelve fellowships, in which altogether 147 members of the Institute were engaged. Applied research was conducted under the auspices of sixty-four other fellowships and occupied the time of 390 members. Of these seventy-six fellowships, forty-seven were multiple and twenty-nine individual, and four had been proceeding for forty years and four others for thirty or more years.

Investigations in the Department of Research in Chemical Physics of the selection rules for ethane-like

- Scientiflc Research Activities of the Mellon Institute, 1954-55. (Annual Report Series, No. 42.) Pp. v+53. (Pittsburgh : Mellon Institute, 1055.) molecules having free internal rotation showed that the selection rules were $D_{3}$ and not $D_{3}$ as reported in the literature. The vibrational spectrum alone does not distinguish between the alternatives of free internal rotation or the staggered configuration. Other investigations showed that in the systems hydrogen chloride-diphenyl ether and hydrogen chlorideanisole at $30-90^{\circ} \mathrm{C}$., while the frequency of the hydrogen chloride bond remains constant, its intensity diminishes as the temperature increases. Investigations of crystallization in stretched polybutadiene and silicones continued, and an X-ray diffraction study of the crystal structure of antimony pentachloride showed that the unit cell is hexagonal and contains two molecules of antimony pentachloride, the trigonal bipyramidal structure of the gaseous molecule being retained in the solid state.

Equipment for separation by thermal diffusion and chromatography has been extended in the Department of Research in Physical Chemistry, and further studies of the design and operation of packed laboratory apparatus for fractionation by thermal diffusion include the effect of packing density and annular width on separating efficiency. Elution chromatography on alumina with graded eluents has been used extensively in the separation of coal tar byproducts, and separate determinations, in which the cuts were examined by ultra-violet spectroscopy, indicated that a naphthalene still residue carcinogenic to mice contained not more than 0.005 per cent of 3:4-benzpyrene. An apparatus built for vapourphase chromatographic investigations has given effective separations and analyses of hydrocarbon mixtures in the range $\mathrm{C}_{4}$ to $\mathrm{C}_{8}$.

The Department of Instrumentation notes a considerable increase in electronic construction and maintenance activities, and has also designed an automatic recording Sward rocker device and an automatic recording instrument for measuring the surface tension of liquids. The preliminary model of a recording balance designed to deflect a recording potentiometer full scale for a $100-\mathrm{mgm}$. change in weight has been found to be capable of being operated at ten thousand times this sensitivity before drift and short-term instability become appreciable. In devising a set of classical equations for the hydraulics of column and plate distillation, the Department of Applied Mathematics found that, for a critical value of the ratio of thickness of liquid layer to radius of cylinder, the mass vapour transport per unit area attained a maximum before the onset of turbulence, which indicates a flooding condition in distillation columns with diameters less than a critical value depending on the viscosity and density of the liquid and vapour.

In co-operation with the Multiple Fellowship on Petroleum, the Department of Analytical Chemistry has been engaged for nearly two years in a fundamental study of the analytical chemistry of organic sulphur compounds; in the course of this a revised Hastings method for the determination of aliphatic sulphides in the analysis of crude oils, by spectro. photometric measurement of the absorptivity of the iodine-sulphide complex, and a modified polarographic method for the determination of elemental sulphur have been developed, and the reduction of heteropoly acids with thiols have been studied. An investigation of the degradation of cellulosic fibres showed that the deterioration of certain fibres depended on the cellulolytic activity of the microorganisms brought in on the raw material and which 